\title{
Laparoscopic surgery for urachal anomalies: Time to shift the paradigm?
}

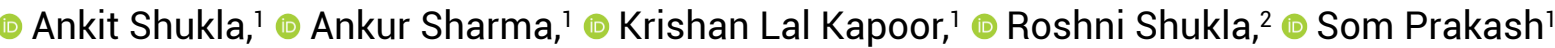 \\ 'Department of Surgery, Civil Hospital, Palampur, India \\ ${ }^{2}$ Department of Radiology, Dr Rajendra Prasad Government Medical College Kangra at Tanda Himachal, Pradesh, India
}

\begin{abstract}
Urachal anomalies are the result of failure of obliteration of the allantois, which connects the bladder to the umbilicus. These anomalies are usually divided into 5 distinct variants based on the site of residual patency across the urachus. Most often, patients present with umbilical discharge, abdominal pain, or recurrent urinary tract infection. The basic investigation tool for diagnosing a case of a urachal remnant is ultrasonography. The traditional approach for treatment of urachal anomalies is open excision. However, the trend has started to shift toward a laparoscopic approach, which has a promising future for dealing with urachal anomalies. Presently described is a case of symptomatic urachal sinus in a female teenager that was dealt with effectively using a laparoscopic approach at a secondary care hospital.
\end{abstract}

Keywords: Laparoscopy; minimally invasive; urachal anomalies; urachal sinus; urachus.

\section{Introduction}

Urachal anomalies are fallout of failure of obliteration of allantois, which connects the bladder to the umbilicus. Persistence of the urachus usually leads to urachal cyst, sinus, diverticulum or patent fistula. Traditional approach for tackling urachal anomalies is open excision through infraumbilical, vertical midline or infraumbilical transverse incision, which have longer convalescence and higher morbidity. However with the inception of minimal invasive surgery the trends have started shifting towards laparoscopic approach, which holds a promising future for tackling urachal anomalies. Herein we report a case of symptomatic female teenager with urachal sinus handled laparoscopically at our secondary care centre.

\section{Case Report}

A fifteen year old female presented to our hospital with the complaint of discharge of pus from the umbilicus. There was previous history of discharge of foul smelling fluid from the umbilicus, which resolved spontaneously. Patient was administered parental antibiotics and the ultrasound of the abdomen revealed patent urachal remnant of approximately $10 \mathrm{~mm}$ diameter. She was discharged after resolution of symptoms and planned for elective laparoscopic removal of the persistent urachal remnant after 6 weeks.

Under general anesthesia patient was catheterized, nasogastric tube inserted and three $5 \mathrm{~mm}$ ports were placed. First port was placed at the palmers point and the second 
port in the midline in the epigastric region and the third port in the left flank at the level of umbilicus. There are several other equally effective approaches of port placement. After the placement of ports and creation of $\mathrm{CO}_{2}$ pneumoperitoneum at $12-15 \mathrm{~mm} \mathrm{Hg}$ the patient was put into Trendelenburg position. The omentum was adherent to the parietal peritoneum infraumbilically and towards its right side, which was separated and the urachal remnant was identified in the midline lying in between the parietal peritoneum and transversalis fascia which was dissected from umbilicus up to the bladder with a combination of sharp dissection with scissors and monopolar cautery. The bladder was filled in retrograde fashion with normal saline through the catheter to identify the urinary bladder. The umbilical end was clipped with titanium clips and divided preserving the umbilicus. The vesical end of the urachal remnant was secured with catgut endoloop suture at the origin from the urinary bladder before division and the specimen was removed using a retrieval bag.

Abdomen was deflated and ports removed after ensuring complete haemostasis and no leakage from the vesical end of the remnant. The procedure was completed successfully in about 35 minutes. Patient was discharged on first postoperative day after uneventful stay in hospital with catheter in situ, which was removed on the tenth post operative day on outpatient basis. On the follow up after six months patient was doing well.

\section{Discussion}

Cabriolus way back in the year 1550 was the first one to describe urachal anomalies. ${ }^{[1]}$ Neufung and Trondsen in the year 1992 and 1993 respectively demonstrated the laparoscopic approach for the management of urachal remnants. ${ }^{[2,3]}$ Urachus is believed to be the vestigial remnant of the embryonal cloaca or the allantois. In the normal process of gestation by mid trimester the urachus involutes, its lumen gets obliterated and is represented by the median umbilical ligament after birth. ${ }^{[4]}$ The urachus arises from apex or the anterosuperior surface of the urinary bladder extending to the umbilicus in the extraperitoneal plane between the parietal peritoneum and the transversalis fascia. It is usually $3-10 \mathrm{~cm}$ long, with a diameter in the range of $8-10 \mathrm{~mm} .^{[5]}$

Urachus histologically consists of three layers the innermost layer of modified transitional epithelium or may be replaced by columnar, middle layer of submucosal con- nective tissue and outermost layer of smooth muscle cells continuous with the detrusor. ${ }^{[6]}$ Mostly the innermost layer of the urachus is composed of transitional epithelium but most common malignancy found is adenocarcinoma, which can be attributed to the metaplasia arising due to chronic inflammation. Urachal anomalies are more common in males with the reported incidence of 1:150000 in infants and it is 1:5000 in adults. ${ }^{[7]}$

Urachal anomalies are divided into five distinct variants based on the site of residual patency across the urachus. They are urachal cyst in which both the ends obliterate leaving a fluid filled cavity anywhere across the tract mostly the lower third, patent urachus or urachal fistula in which the whole tract fails to obliterate, umbilical- urachal sinus in which the vesical end obliterates but the umbilical end fails to obliterate and presents as an out pouching just below the umbilicus, vesicourachal diverticulum is rare in which the vesical end fails to obliterate and lastly the variant with alternating draining sinus into the bladder and umbilicus considered by some as the subtype of umbilicalurachal sinus. ${ }^{[8]}$ Of these variants the urachal cysts are the most commonly found approximately in $69 \%$ of children, urachal sinus is found in around $18 \%$ cases and the vesicourachal diverticulum in 3\%..$^{[9]}$

Urachal remnants have a variable presentation and the type of the urachal anomaly, dictates the clinical presentation however it is often delayed due to nonspecific symptoms or absence of it. History and clinical examination has a very valuable role. Mostly patients present as umbilical discharge, abdominal pain, recurrent urinary tract infection or sometimes discovered incidentally. ${ }^{[10]}$ Urachal anomalies have to be differentiated from the anomalies of vitelline ducts such as Meckel's diverticulum, patent omphalomesentric duct or omphalitis. Laparoscopy is highly efficient in differentiating these anomalies and has an upper edge over the open approach. Sometimes they are associated with inguinal hernia, hypospadiasis, vesicouretral reflux, crossed renal ectopia, anal atresia, meatal stenosis, cryptoorchidism and ureteropelvic obstruction. ${ }^{[1]}$

Elementary investigation for diagnosing a case of urachal remnant is ultrasonography; which has high accuracy approaching $90 \%$, especially in children..$^{[5,12]}$ Computed tomography, sinography, micturating cysto-urethrogram, and magnetic resonance imaging are reserved for evaluating complicated cases, or in case of high index of diagnostic suspicion in an equivocal ultrasonography and cases suspicious of malignancy. ${ }^{[12]}$ Contrast enhanced 
computed tomography is valuable tool to rule out malignancy in urachal remnant. In some cases calcifications are noticed in the urachal mass peripherally or centrally and these calcifications in a case of urachal remnant are pathogonomic of urachal adenocarcinoma.

Until recently, the urachal remnants were treated with excision through infraumbilical vertical midline or infraumbilical transverse incision, which has longer convalescence and higher morbidity. The inclination of the surgeons is shifting from the time honored open approach as the laparoscopic surgery is a better alternative. It displays an astounding view of the urachal anatomy without disturbing the normal anatomical planes, is cosmetically better, has less postoperative pain, is less invasive, cost effective and has faster recovery as compared to the open excision. Laparoscopic approach also helps to excise the urachal remnant completely under better vision lowering the risk of malignancy. ${ }^{[13]}$

\section{Conclusion}

Laparoscopic approach for managing urachal remnants is a better alternative than the open approach and has all the traits of a gold standard procedure. Complete laparoscopic removal of urachal remnants with or without a cuff of bladder tissue is safe, less invasive, provides excellent visualization of urachal anatomy, effective, less painful, has early recovery, is better cosmetically and definitely superior to its open counterpart. However the paucity of the cases have lead to fewer trials and standardization of the procedure, which is the main hurdle for the laparoscopic approach being considered gold standard procedure for urachal anomalies.

\section{Disclosures}

Informed Consent: Written informed consent was obtained from the parents of the patient for the publication of the case report and the accompanying images.
Peer-review: Externally peer-reviewed.

Conflict of Interest: None declared.

\section{References}

1. Kwok CM. Infected Urachal Cyst in an Adult: A Laparoscopic Approach. Case Rep Gastroenterol 2016;10:269-74. [CrossRef]

2. Neufang T, Ludtke FE, Lepsien G. Laparoscopic excision of an urachal fistula-a new therapy for a rare disorder, Minim Invasive Ther Allied Technol 1992;1:245-9.

3. Trondsen E, Reiertsen O, Rosseland AR. Laparoscopic excision of urachal sinus. Eur J Surg 1993;159:127-8.

4. Scheye T, Vanneuville G, Amara B, Francannet P, Dechelotte $P$, Campagne D. Anatomic basis of pathology of the urachus. Surg Radiol Anat 1994;16:135-41. [CrossRef]

5. Yu JS, Kim KW, Lee HJ, Lee YJ, Yoon CS, Kim MJ. Urachal remnant diseases: spectrum of CT and US findings. Radiographics 2001;21:451-61. [CrossRef]

6. Frimberger D, Kropp BP. Bladder anomalies in children. In: Wein AJ, editor. Urology. 11th ed. Philadelphia, Pa: Elsevier; 2016. p. 3173-81.

7. Chiarenza SF, Scarpa MG, D'Agostino S, Fabbro MA, Novek SJ, Musi L. Laparoscopic excision of urachal cyst in pediatric age: report of three cases and review of the literature. $\mathrm{J}$ Laparoendosc Adv Surg Tech A 2009;19:S183-S6. [CrossRef]

8. Kingsleyand CE, Nigel JP. Infected urachal cyst in an adult: a case report and review of the literature. Cases Journal 2009;2: 6422. [CrossRef]

9. Nogueras-Ocaña $M$, Rodríguez-Belmonte $R$, Uberos-Fernández J, Jiménez-Pacheco A, Merino-Salas S, Zuluaga-Gómez A. Urachal anomalies in children: surgical or conservative treatment?. J Pediatr Urol 2014;10:522-6. [CrossRef]

10. Gollu G, Kucuk G, Ates U, Turedi B, Khanmammadov F, Yagmurlu $A$, et al. Laparoscopic management of urachal remnants in children. J Exp Clin Med 2017;34:89-92.

11. Copp HL, Wong IY, Krishnan C, Malhotra S, Kennedy WA. Clinical presentation and urachal remnant pathology: implications for treatment. J Urol 2009;182:1921-4. [CrossRef]

12. Galati V, Donovan B, Ramji F, Campbell J, Kropp BP, Frimberger $D$. Management of urachal remnants in early childhood. J Urol 2008;180:1824-7. [CrossRef]

13. Whitehead A, Arthur LG, Prasad R. Laparoscopic vs open excision of urachal remnants in children. J Surgery 2015;2:3. 